Available online at www.sciencedirect.com

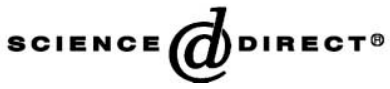

Applied Thermal

ENGINEERING

PERGAMON

Applied Thermal Engineering 23 (2003) 325-340

www.elsevier.com/locate/apthermeng

\title{
Performance investigation of plain and finned tube evaporatively cooled heat exchangers
}

\author{
Ala Hasan *, Kai Sirén \\ Laboratory of Heating, Ventilating and Air Conditioning, Helsinki University of Technology, P.O. Box 4400, \\ FIN-02015 Hut, Finland
}

Received 4 March 2002; accepted 11 October 2002

\begin{abstract}
The performance of two evaporatively cooled heat exchangers is investigated under similar operating conditions of air flow rates and inlet hot water temperatures. The heat exchangers are plain and plate-finned circular tube types which occupy the same volume. Spray water, which is circulated in a closed circuit, is injected onto the exposed surfaces of the tubes and fins. The contact between air and spray water results in evaporative heat transfer. The tubes are copper, $10 \mathrm{~mm}$ o.d. The finned configuration is constructed by introducing $0.5 \mathrm{~mm}$ thick copper plates between the tubes, with a total area ratio of four. A substantial increase in heat transfer takes place for the plate-finned tubes. The increase is $92-140 \%$ for air velocities from 1.66 to $3.57 \mathrm{~m} \mathrm{~s}^{-1}$. A model is used to calculate the thermal performance of the plain and finned tubes assuming a constant spray water temperature in the heat exchanger. The wet-finned surfaces show low fin efficiency compared with dry surfaces. An energy index defined as the ratio of volumetric thermal conductance to air pressure drop per unit length is found to be close for the two heat exchangers. This reveals higher thermal utilisation of the occupied volume by the finned tubes with the same energy index.

(C) 2002 Elsevier Science Ltd. All rights reserved.
\end{abstract}

Keywords: Heat exchanger; Evaporative; Wet; Plate-fin

\section{Introduction}

Evaporatively cooled heat exchangers can achieve heat transfer rates higher than dry heat exchangers. They have many applications in the fields of air-conditioning, refrigeration, and power plants. Heat transfer takes place from a hot fluid, flowing inside tubes, to air through a

\footnotetext{
* Corresponding author. Tel.: +358-9-451-3598; fax: +358-9-451-3418.

E-mail address: ala.hasan@hut.fi (A. Hasan).
} 


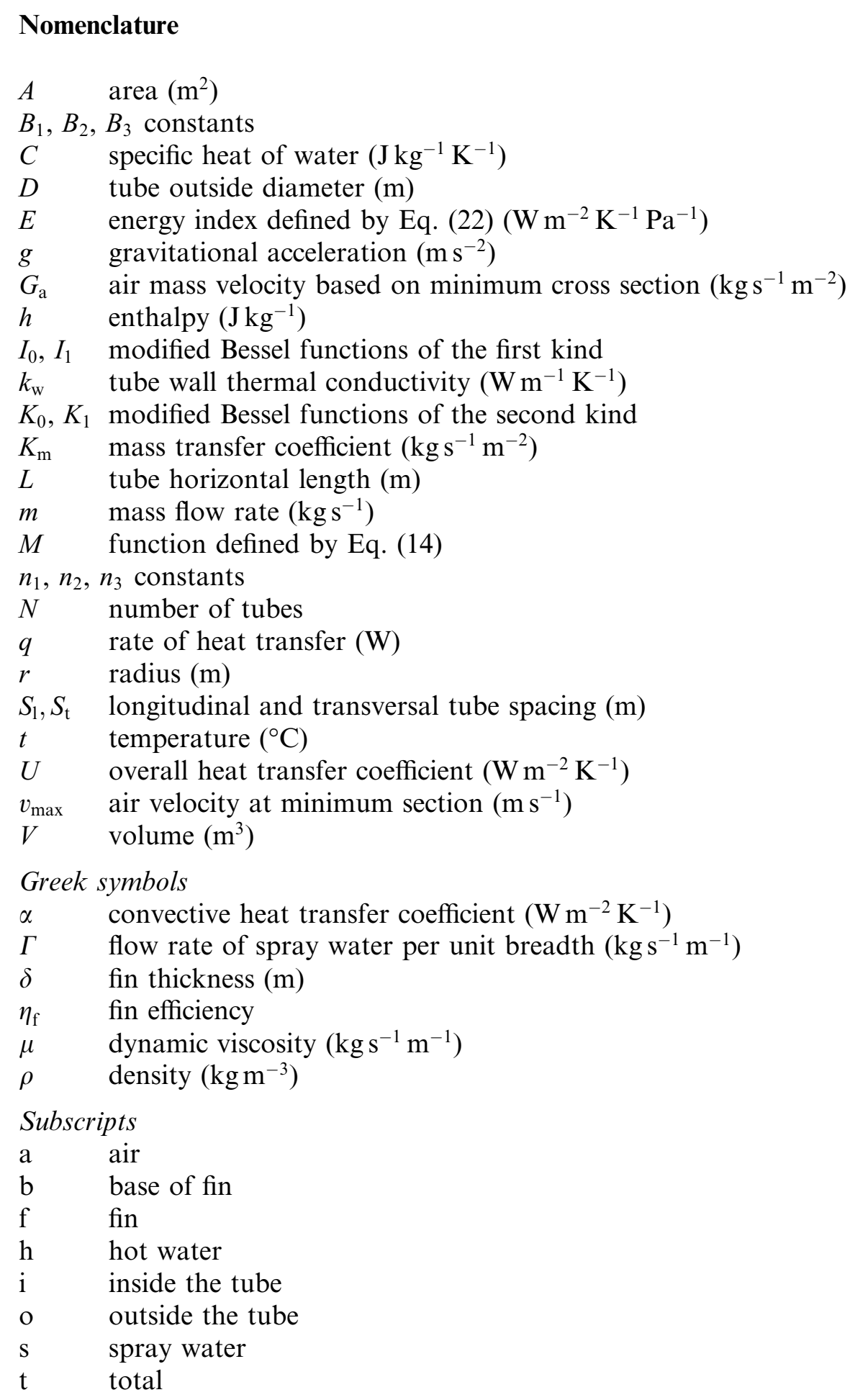




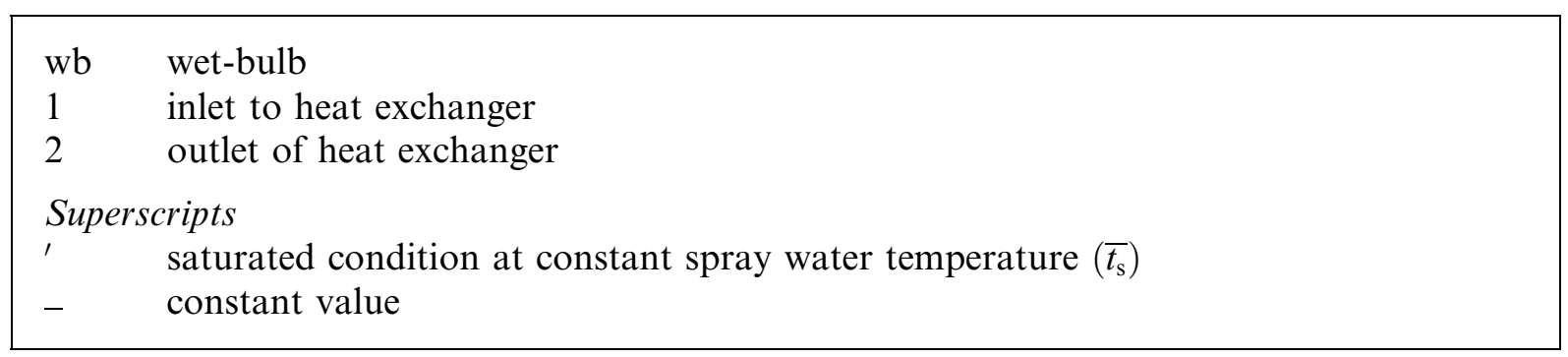

water film which is formed by spraying water onto the heat exchanger surface. Spray water is circulated in a closed circuit. Heat transfer to air is in sensible and latent forms. The latent heat transfer makes up a major part and is produced by the evaporation of a small amount of the spray water into the air stream. When compared with dry heat exchangers, wet heat exchangers can achieve lower temperatures because the air wet-bulb temperature is theoretically, the ultimate limit of the air-water direct contact process. The hot fluid is not in a direct contact with air because of the cleanliness requirements for these two fluids. Closed wet cooling towers (CWCTs), evaporative fluid coolers and evaporative condensers are examples of this application. Evaporative fluid coolers usually operate at higher temperature levels than CWCTs, however the thermal analysis is similar. Evaporative condensers work at a constant condensing temperature. Fig. 1a shows the arrangement of an evaporatively cooled heat exchanger.

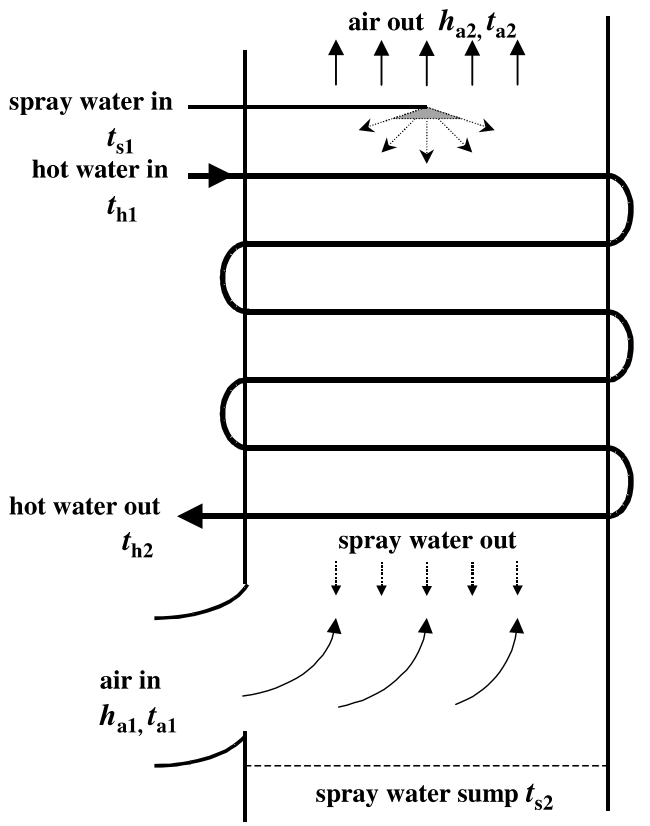

(a)

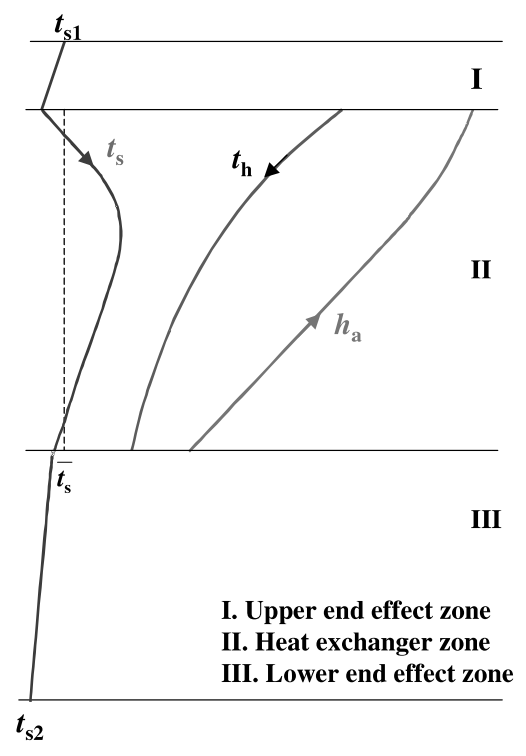

(b)

Fig. 1. (a) Schematic of the evaporatively cooled heat exchanger. (b) Expected temperature and enthalpy distribution along the exchanger. 
Previous work on plain tubes includes empirical data for evaporative fluid coolers. The thermal performance was subjected to mathematical and experimental analysis in the early work of Parker and Treybal [1], Mizushina et al. [2,3], and Niitsu et al. [4]. A model was presented by Erens [5] to predict the performance of a plain tube evaporative liquid cooler with plastic fills. Tsay [6] performed a numerical analysis to study the heat and mass transfer characteristics of wet surface heat exchangers. All of these works were for counterflow arrangement. Dreyer and Erens [7] carried out experimental work on plain tubes in crossflow arrangement and compared the heat and mass transfer coefficients with counterflow arrangement. Peterson et al. [8] applied transfer coefficients calculated according to Parker and Treybal's correlation [1] to estimate the performance of plain tube evaporative condensers.

CWCTs are usually used in industry to reject heat to atmospheric air. They appeared to have high coefficients of performance when used with chilled ceilings for cooling of buildings as presented by Hasan and Sirén [9], where a computational model was developed for the thermal performance of CWCTs. The model was based on finite difference. It took into consideration variations of spray water temperature along the tower. Simplification of the analytical model was obtained by Hasan and Gan [10] by an assumption of constant spray water temperature along the tower.

Niitsu et al. [4] tested also banks of finned tubes in evaporative liquid coolers. The fins were circular, $42.6 \mathrm{~mm}$ diameter. The tubes were $16 \mathrm{~mm}$ outside diameter, in a staggered arrangement. Two fin spacings were tested $(6.1$ and $11 \mathrm{~mm})$. They concluded that the finned bank has much lower heat and mass transfer coefficients for the spray water side compared with the plain bank. This was attributed to possible water hold up between the fins and low fin efficiency for the wet fins. Kried et al. [11] proposed a theoretical model for deluged (flooded) finned heat exchangers. By introducing appropriate parameters, they transformed wet surface heat transfer equations to approximated equations which were in analogy to dry heat transfer equations. Leidenfrost and Korenic [12] presented a mathematical model for finned tube evaporative condensers based on a graphical procedure which was executed by a computer program in a stepwise integration. They estimated the mass transfer coefficients from dry heat transfer coefficients, and the Lewis relation was assumed to equal unity. To our knowledge, only Niitsu et al. [4] presented a comparison of performance of plain and circular-finned tubes. The literature lacks more data for comparing the performance of plain and finned tubes.

The objective of this work is to empirically compare the thermal and hydraulic performance and the transfer coefficients of plain and plate-finned tubes used in evaporatively cooled heat exchangers. The operating parameters are chosen close to the characteristic conditions of CWCTs.

\section{Theory}

\subsection{Plain tubes}

A one-dimensional computational model was presented in [9] for the heat-mass transfer process in CWCTs. The Merkel equation [13] was implemented for the energy transfer between the air-spray water interface (assumed to be saturated at the spray water temperature) and the air bulk, with the assumption of unity for the Lewis relation. The amount of water evaporation was 
calculated from the mass balance for the contact between spray water and air. The analysis included spray water temperature variation along the tower. In [10], and for purpose of simplification, the spray water temperature was assumed to be constant $\left(\overline{t_{\mathrm{s}}}\right)$. This assumption showed small differences in the calculated heat load when compared with that obtained from the computational model for a CWCT prototype used with chilled ceilings in cooling of buildings. Therefore, the assumption of constant spray water temperature $\left(\overline{t_{\mathrm{s}}}\right)$ and the relevant heat transfer equations from [10] will be considered in the current analysis. For the heat transfer from the hot water to the spray water film through the tube wall

$$
\frac{U_{\mathrm{o}} A_{\mathrm{t}}}{m_{\mathrm{h}} C}=\ln \left(\frac{t_{\mathrm{h} 1}-\overline{t_{\mathrm{s}}}}{t_{\mathrm{h} 2}-\overline{t_{\mathrm{s}}}}\right)
$$

where $U_{\mathrm{o}}$ is the overall heat transfer coefficient based on $A_{\mathrm{t}}$ (total outside area of the tubes)

$$
\frac{1}{U_{\mathrm{o}}}=\frac{1}{\alpha_{\mathrm{h}}} \frac{r_{\mathrm{o}}}{r_{\mathrm{i}}}+\frac{r_{\mathrm{o}}}{k_{\mathrm{w}}} \ln \left(\frac{r_{\mathrm{o}}}{r_{\mathrm{i}}}\right)+\frac{1}{\alpha_{\mathrm{s}}}
$$

where $\alpha_{\mathrm{h}}$ is the heat transfer coefficient between the hot water and the internal wall, and $\alpha_{\mathrm{s}}$ is heat transfer coefficient between the external wall and the spray water bulk. Heat transfer between the air-spray water interface and the moist air is due to sensible and latent heats. The latent heat has a major effect and is due to the evaporation of a small amount of spray water to the air. The Merkel equation [13] and the air enthalpy change between the inlet and outlet yields

$$
\frac{K_{\mathrm{m}} A_{\mathrm{t}}}{m_{\mathrm{a}}}=\ln \left(\frac{h_{\mathrm{a}}^{\prime}-h_{\mathrm{a} 1}}{h_{\mathrm{a}}^{\prime}-h_{\mathrm{a} 2}}\right)
$$

where $h_{\mathrm{a}}^{\prime}$ is the saturated air enthalpy taken at the spray water temperature $\overline{t_{\mathrm{s}}}$. Eqs. (1) and (3) comply with the log-mean definitions for temperature and enthalpy differences, respectively. The coefficients $U_{\mathrm{o}}$ and $K_{\mathrm{m}}$ in these equations are overall heat and mass transfer coefficients, respectively, which replace local coefficients. Assuming constant spray water temperature, the total energy balance for the flowing fluids between the inlet and outlet of the heat exchanger is

$$
m_{\mathrm{h}} C\left(t_{\mathrm{h} 1}-t_{\mathrm{h} 2}\right)=m_{\mathrm{a}}\left(h_{\mathrm{a} 2}-h_{\mathrm{a} 1}\right)
$$

The expected temperature and enthalpy distributions inside the heat exchanger according to the analysis presented in [9] are shown in Fig. 1b. In the present work, the constant spray water temperature $\overline{t_{\mathrm{s}}}$ will be taken equal to the inlet spray water temperature $t_{\mathrm{s} 1}$ measured from the experiments. This assumption seems acceptable according to Fig. $1 \mathrm{~b}$.

\subsection{Plate-finned tubes}

The same assumptions will be considered for the finned tubes; the spray water temperature will be assumed to be constant on the fin surface and the bare-tube between the fins. By considering a small element including a fin as shown by Fig. $2 \mathrm{a}$, the heat transfer from the hot water to air via the spray water film will be studied. 

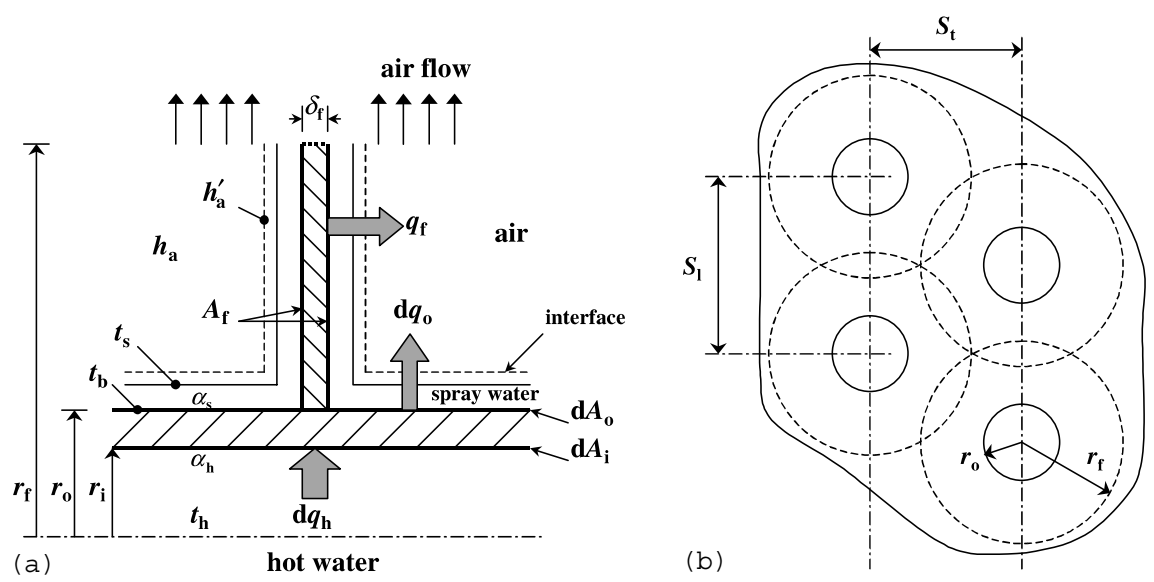

Fig. 2. (a) Element in a finned tube. (b) Approximation of a plate-fin by circular fins.

\subsubsection{Heat transfer from the hot water to the spray water}

Heat transfer from the hot water to the bare-tube outer surface and the fin base (both at temperature $t_{\mathrm{b}}$ ) is

$$
\mathrm{d} q_{\mathrm{h}}=\frac{\left(t_{\mathrm{h}}-t_{\mathrm{b}}\right) \mathrm{d} A_{\mathrm{i}}}{\frac{1}{\alpha_{\mathrm{h}}}+\frac{r_{\mathrm{i}}}{k_{\mathrm{w}}} \ln \left(\frac{r_{\mathrm{o}}}{r_{\mathrm{i}}}\right)}
$$

where $\mathrm{d} A_{\mathrm{i}}$ is the internal area of the tube. For the spray water, heat received from the hot water $\mathrm{d} q_{\mathrm{h}}$ is by two means: heat from the fin surface $q_{\mathrm{f}}$ and heat from the bare-tube surface $\mathrm{d} q_{\mathrm{o}}$

$$
\mathrm{d} q_{\mathrm{h}}=q_{\mathrm{f}}+\mathrm{d} q_{\mathrm{o}}
$$

Heat transferred from the fin surface in terms of fin efficiency $\eta_{\mathrm{f}}$ is

$$
q_{\mathrm{f}}=\eta_{\mathrm{f}} \alpha_{\mathrm{s}}\left(t_{\mathrm{b}}-\overline{t_{\mathrm{s}}}\right) A_{\mathrm{f}}
$$

The heat transfer coefficient $\alpha_{\mathrm{s}}$ is assumed to be constant for the surface of the fin and the baretube. Heat transfer from the surface of bare-tube between the fins $\mathrm{d} A_{\mathrm{o}}$ is

$$
\mathrm{d} q_{\mathrm{o}}=\alpha_{\mathrm{s}}\left(t_{\mathrm{b}}-\overline{t_{\mathrm{s}}}\right) \mathrm{d} A_{\mathrm{o}}
$$

Substituting for $q_{\mathrm{f}}$ and $\mathrm{d} q_{\mathrm{o}}$ from Eqs. (7) and (8) in Eq. (6) gives

$$
\mathrm{d} q_{\mathrm{h}}=\alpha_{\mathrm{s}}\left(t_{\mathrm{b}}-\overline{t_{\mathrm{s}}}\right)\left(\eta_{\mathrm{f}} A_{\mathrm{f}}+\mathrm{d} A_{\mathrm{o}}\right)
$$

Eliminating $t_{\mathrm{b}}$ between Eqs. (5) and (9), the heat lost from the hot water between the inlet and outlet of the element can be written as

$$
\mathrm{d} q_{\mathrm{h}}=\frac{t_{\mathrm{h}}-\overline{t_{\mathrm{s}}}}{\frac{1}{\alpha_{\mathrm{s}}}\left(\frac{1}{\eta_{\mathrm{f}} A_{\mathrm{f}}+\mathrm{d} A_{\mathrm{o}}}\right)+\frac{1}{\mathrm{~d} A_{\mathrm{i}}}\left[\frac{1}{\alpha_{\mathrm{h}}}+\frac{r_{\mathrm{i}}}{k_{\mathrm{w}}} \ln \left(\frac{r_{\mathrm{o}}}{r_{\mathrm{i}}}\right)\right]}=-m_{\mathrm{h}} C \mathrm{~d} t_{\mathrm{h}}
$$

Integrating Eq. (10) from the inlet to the outlet of the heat exchanger yields Eq. (1), in which $U_{\mathrm{o}} A_{\mathrm{t}}$ for the finned heat exchanger is defined as 


$$
\frac{1}{U_{\mathrm{o}} A_{\mathrm{t}}}=\frac{1}{\alpha_{\mathrm{s}}}\left(\frac{1}{\eta_{\mathrm{f}} A_{\mathrm{ft}}+A_{\mathrm{ot}}}\right)+\frac{1}{A_{\mathrm{it}}}\left[\frac{1}{\alpha_{\mathrm{h}}}+\frac{r_{\mathrm{i}}}{k_{\mathrm{w}}} \ln \left(\frac{r_{\mathrm{o}}}{r_{\mathrm{i}}}\right)\right]
$$

where the heat transfer areas in this equation are the total for the heat exchanger: $A_{\mathrm{ft}}$ is the total finned area, $A_{\mathrm{ot}}$ is the total outer surface area of the bare-tubes between the fins, and $A_{\mathrm{it}}$ is the total inner area of the tubes.

Threlkeld [14] referred to a procedure for the approximation of a plate-fin by circular fins having equivalent performance. The equivalent radius of the circular fin $r_{\mathrm{f}}$ is

$$
r_{\mathrm{f}}=\sqrt{\frac{S_{\mathrm{l}} S_{\mathrm{t}}}{\pi}}
$$

where $S_{1}$ and $S_{\mathrm{t}}$ are the longitudinal and transversal tube spacing, respectively, as per Fig. 2b. For heat transfer from a circular fin of uniform thickness $\delta_{\mathrm{f}}$ to the surroundings at temperature $\bar{t}_{\mathrm{s}}$, the exact solution for the fin efficiency $\eta_{\mathrm{f}}$ is presented in [15]

$$
\eta_{\mathrm{f}}=\frac{2 r_{\mathrm{o}}}{M\left(r_{\mathrm{f}}^{2}-r_{\mathrm{o}}^{2}\right)} \frac{K_{1}\left(M r_{\mathrm{o}}\right) I_{1}\left(M r_{\mathrm{f}}\right)-K_{1}\left(M r_{\mathrm{f}}\right) I_{1}\left(M r_{\mathrm{o}}\right)}{K_{1}\left(M r_{\mathrm{f}}\right) I_{0}\left(M r_{\mathrm{o}}\right)+K_{0}\left(M r_{\mathrm{o}}\right) I_{1}\left(M r_{\mathrm{f}}\right)}
$$

where $I_{0}, I_{1}$ are the modified Bessel functions of the first kind, order 0 and 1, respectively, and $K_{0}$, $K_{1}$ are the modified Bessel functions of the second kind, order 0 and 1, respectively. $M$ is defined as

$$
M=\sqrt{\frac{2 \alpha_{\mathrm{s}}}{k_{\mathrm{f}} \delta_{\mathrm{f}}}}
$$

where $k_{\mathrm{f}}$ is the fin thermal conductivity. The simple approximate formula by Schmidt [16] will be used to calculate $\eta_{\mathrm{f}}$ instead of Eq. (13)

$$
\eta_{\mathrm{f}}=\frac{\tanh \left(M r_{\mathrm{o}} \phi\right)}{M r_{\mathrm{o}} \phi}
$$

where

$$
\phi=\left(\frac{r_{\mathrm{f}}}{r_{\mathrm{o}}}-1\right)\left[1+0.35 \ln \left(\frac{r_{\mathrm{f}}}{r_{\mathrm{o}}}\right)\right]
$$

\subsubsection{Heat transfer from the spray water to the moist air}

Heat is transferred from the spray water to the moist air through the air-spray water interface. The liquid side of the interface offers a negligible resistance to heat transfer. Therefore, the interface could be assumed to be saturated at the spray water temperature. Heat transfer consists of sensible heat and latent heat due to mass transfer. Eq. (3) can be used to calculate the heat transfer from the interface to the air stream, where $A_{\mathrm{t}}$ will refer to the total wet surface area of the finnedtubes (sum of $A_{\mathrm{ft}}$ and $A_{\mathrm{ot}}$ ).

For the total heat balance of the fluids flowing inside the heat exchanger, Eq. (4) can be used between the heat exchanger inlet and outlet.

A model is developed by solving the three Eqs. (1), (3), and (4). When the geometry of the heat exchanger and the transfer coefficients $\left(\alpha_{\mathrm{s}}, \alpha_{\mathrm{h}}, K_{\mathrm{m}}\right)$ are specified, we can feed in the inlet operating conditions $\left(m_{\mathrm{h}}, m_{\mathrm{a}}, t_{\mathrm{h} 1}, h_{\mathrm{a} 1}\right)$ to find three unknowns $\left(t_{\mathrm{h} 2}, h_{\mathrm{a} 2}\right.$, and $\left.\overline{t_{\mathrm{s}}}\right)$, noting that $h_{\mathrm{a}}^{\prime}$ is calculated from $\overline{t_{\mathrm{s}}}$. 


\section{Experimental work}

Fig. 3 shows a schematic diagram of the experimental test system. The system consisted of three circuits (air, hot water, and spray water). An electric heater provided the heat load in the hot water circuit. Two circulating pumps were used, one for the hot water, and the other one for the spray water. Spray water was injected onto the surfaces of the heat exchanger by a spray nozzle. Air was introduced to the heat exchanger by means of a fan. The air flow rate was measured by an orifice meter. A differential pressure meter measured the pressure drop of air flowing across the test section. Inlet and outlet temperatures were measured by thermocouples for the three fluids flowing in the heat exchanger. Two thermocouples were used to measure the temperature in each measuring station, where the average was taken. All thermocouples were connected to a data logger which also showed air humidity readings at the inlet and outlet. A mist eliminator was installed up-stream of the outlet air measurement station. The test section and interconnecting piping were insulated from the surroundings. One side of the test section was made of transparent plastic to visualise spray water behaviour. All instruments used in the test were calibrated prior to measurements.

\subsection{Heat exchanger dimensions}

The test cross section is $88 \mathrm{~mm} \times 130 \mathrm{~mm}$, having a length of $250 \mathrm{~mm}$. The tubes are circular copper tubes arranged in a staggered equilateral pitch of $2.8 \mathrm{D}$ in eight rows. The number of tubes

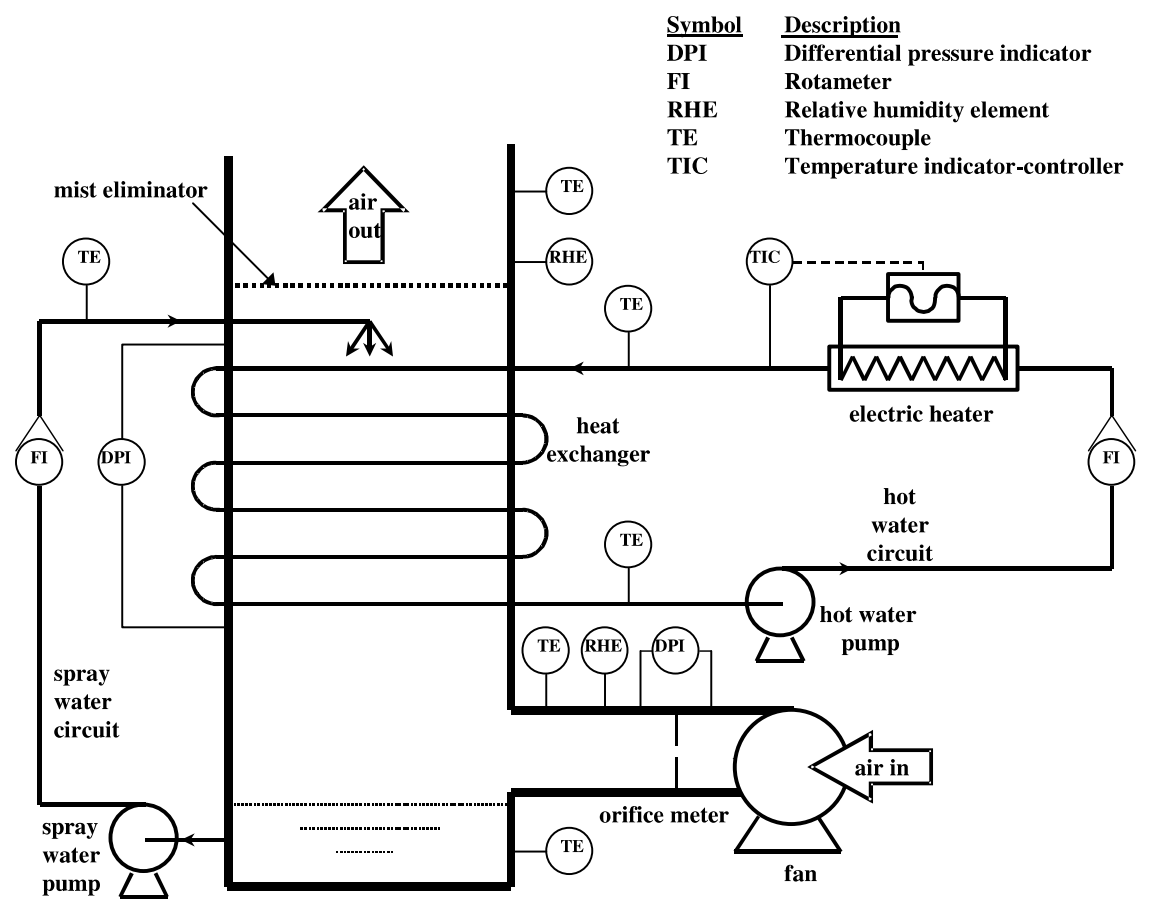

Fig. 3. Schematic diagram of the experimental test system. 
is four, tube outside diameter is $10 \mathrm{~mm}$, and tube horizontal length is $88 \mathrm{~mm}$. The finned tubes are constructed by adding fin-plates between the plain tubes. The fins are copper plates with dimensions of $194 \mathrm{~mm} \times 126 \mathrm{~mm}$. The number of plate-fins is six, each of $0.5 \mathrm{~mm}$ thickness. Fin spacing is $12 \mathrm{~mm}$, which is considered to ease spray water flow along the fins. The finned plates were soldered to the tubes. The two heat exchangers occupy the same volume and the ratio of total contact area (finned tubes/plain tubes) is four.

\subsection{Test set-up data}

\subsubsection{Air flow}

Three air flow rates were considered: $0.0151,0.0235$, and $0.0323 \mathrm{~kg} \mathrm{~s}^{-1}$, which correspond to air mass velocities of $1.9,3.0$, and $4.08 \mathrm{~kg} \mathrm{~s}^{-1} \mathrm{~m}^{-2}$, respectively. These are in the average range of air mass velocities from the literature. Air velocities in the minimum flow area were 1.58, 2.45, 3.4 $\mathrm{m} \mathrm{s}^{-1}$ for plain tubes, and 1.66, 2.57, $3.57 \mathrm{~m} \mathrm{~s}^{-1}$ for finned tubes, respectively. For the finned tubes, the relative increase in air velocity due to the decrease of flow area was about $5 \%$ for a dry section. Inlet air humidity was not controlled and was dependent on the condition of the supply air.

\subsubsection{Hot water}

The hot water flow rate was constant during the experiments and equal to $0.1141 \mathrm{~s}^{-1}\left(4101 \mathrm{~h}^{-1}\right)$. Three nominal inlet hot water temperatures $\left(30,32\right.$ and $\left.34{ }^{\circ} \mathrm{C}\right)$ were considered. These temperatures are in the range of general CWCT application, but are high for cooling of buildings. However, they were considered to obtain measurable temperature differentials and minimise relative errors.

\subsubsection{Spray water}

A value of $1.78 \mathrm{~kg} \mathrm{~s}^{-1} \mathrm{~m}^{-2}$ was taken for the parameter $\Gamma / D$ for the plain tubes, which is an average value from the literature. The spray water flow per unit breadth $\Gamma$ is defined for staggered tubes as $m_{\mathrm{s}} / 4 N L$, where $N$ is the number of tubes and $L$ is the tube horizontal length. Therefore, spray water flow rate $m_{\mathrm{s}}$ for the plain tubes was $0.0251 \mathrm{~s}^{-1}\left(90 \mathrm{lh}^{-1}\right)$. When using this flow rate for the finned tubes, it was noticed that it was insufficient to wet all the exposed surfaces which was due to the utilisation of more area in the finned configuration. Therefore, the spray water flow rate was increased to $0.0551 \mathrm{~s}^{-1}\left(200 \mathrm{lh}^{-1}\right)$ for the finned tubes. The criterion was to ensure wetting of all exposed surfaces.

\section{Results and discussion}

The energy balance for the three streams flowing inside the heat exchangers (air, hot water, and spray water) was checked during the collection of measurements data. Heat loss less than $5 \%$ in the heat balance was tolerated. To exclude end effect coming from air-spray water contact in the lower end, air enthalpy is taken from the bottom of the tube bank to the air outlet when applying Eq. (4). Finlay and Harris [17] referred to water hold up between the plate-fins to explain the results obtained by Niitsu et al. [4]. Such behaviour was not noticed in our observations of the 


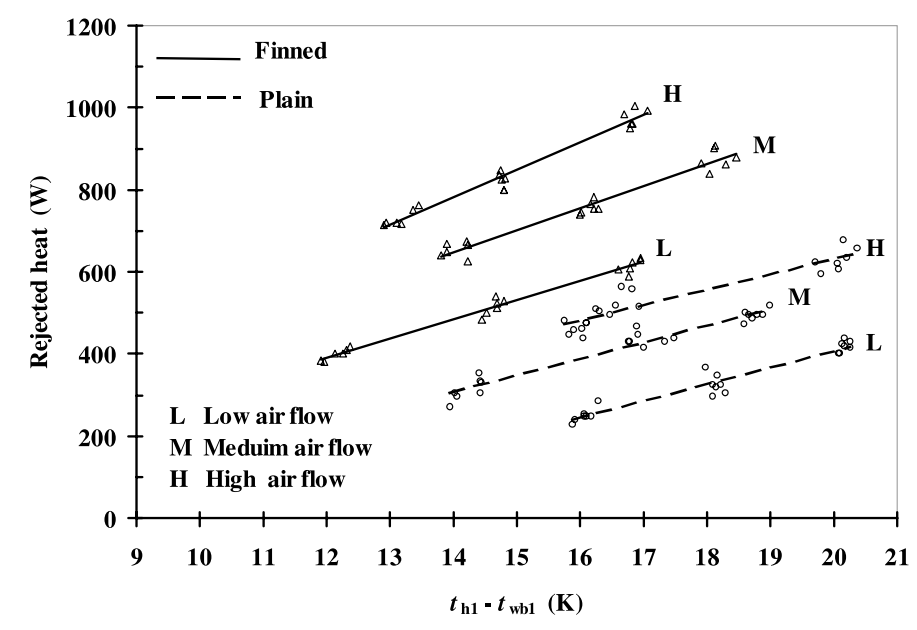

Fig. 4. Measured thermal performance of the plain and finned tubes.

current work. The inlet spray water temperature was slightly higher than the sump temperature, which is attributed to water heat up produced by the spray water pump operation.

In Fig. 4, the thermal performance of the plain and finned tubes is shown in terms of the rejected heat on the vertical axis for the three air flow rates $(L, M$, and $H)$. The horizontal axis represents the difference between the inlet hot water temperature $\left(t_{\mathrm{h} 1}\right)$ and the outdoor air wetbulb temperature $\left(t_{\mathrm{wb}}\right)$, which could be considered as a measure of the temperature-difference potential available at the inlet. For a specific tube geometry (plain or finned), the influence of higher air flow rate or higher temperature-difference potential is higher rejected heat. Major improvements in heat transfer take place when using the plate-finned tubes. For example, for $t_{\mathrm{h} 1}-t_{\mathrm{wb}}=16 \mathrm{~K}$, the ratio of heat transfer (finned to plain) ranges from 1.92 to 2.40 for the implemented air flow rates.

A relationship obtained by McAdams et al. [18] was implemented by Parker and Treybal [1] to define $\alpha_{\mathrm{s}}$ for falling film outside horizontal tubes:

$$
\alpha_{\mathrm{s}}=B_{1}\left(\frac{C \mu}{k}\right)^{1 / 3}\left(\frac{\mu^{2}}{\rho^{2} g}\right)^{1 / 9}\left(\frac{2}{\pi D}\right)^{1 / 3}\left(\frac{4 \Gamma}{\mu}\right)^{1 / 3}\left(\frac{k^{3} \rho^{2} g}{\mu^{2}}\right)^{1 / 3}
$$

where $B_{1}$ is a constant, $C$ is the specific heat $\left(\mathrm{J} \mathrm{kg}^{-1} \mathrm{~K}^{-1}\right), \mu$ is the dynamic viscosity $\left(\mathrm{kg} \mathrm{s}^{-1} \mathrm{~m}^{-1}\right)$, $\rho$ density $\left(\mathrm{kg} \mathrm{m}^{-3}\right), k$ thermal conductivity $\left(\mathrm{W} \mathrm{m}^{-1} \mathrm{~K}^{-1}\right)$, and $g$ is the gravitational acceleration $\left(\mathrm{m} \mathrm{s}^{-2}\right)$. The physical properties could be evaluated for any operating temperature, and Eq. (17) is reduced to the following form:

$$
\alpha_{\mathrm{s}}=B_{2}\left(\frac{\Gamma}{D}\right)^{B_{3}}
$$

where $B_{2}$ and $B_{3}$ are constants. This equation indicates higher heat transfer coefficient $\alpha_{\mathrm{s}}$ for higher spray water flow rate.

The spray water flow rate for the finned tubes was $0.0551 \mathrm{~s}^{-1}\left(2001 \mathrm{~h}^{-1}\right)$, while for the plain tubes it was $0.0251 \mathrm{~s}^{-1}\left(901 \mathrm{~h}^{-1}\right)$. To investigate the effect of the spray water flow rate increase on 
the finned tubes heat transfer, it was increased by 25\% (a spray water flow rate of $0.0691 \mathrm{~s}^{-1}(250$ $1 \mathrm{~h}^{-1}$ ) was used). Experimental results showed that the effect was negligible. This can be confirmed by calculating $U_{\mathrm{o}}$ from Eq. (11). The $25 \%$ increase in $m_{\mathrm{s}}$ results in $7.7 \%$ increase in $\alpha_{\mathrm{s}}$ according to Eq. (18) (where $B_{3}=1 / 3$ ). When calculating $U_{\mathrm{o}}$ from Eq. (11), it is found that the $25 \%$ increase of $\alpha_{\mathrm{s}}$ produces $<3 \%$ increase in $U_{\mathrm{o}}$ (or rejected heat). This indicates that the increase in the thermal performance is due to the use of the fins.

For the plain tubes, the Reynolds number for spray water defined as $(4 \Gamma / \mu)$ is 72 , which is laminar. Available empirical correlations are in the broad range for the value of $\alpha_{\mathrm{s}}$. For plain circular tubes and $\Gamma / D=1.78 \mathrm{~kg} \mathrm{~s}^{-1} \mathrm{~m}^{-2}$, the value of $\alpha_{\mathrm{s}}\left(\mathrm{W} \mathrm{m}^{-2} \mathrm{~K}^{-1}\right)$ is 2544 according to Mizushina et al. [2], 1696 according to Parker and Treybal [1], and 1290 according to Niitsu et al. [4]. The latter authors presented a correlation for finned tubes which gives $\alpha_{\mathrm{s}}=744 \mathrm{~W} \mathrm{~m}^{-2} \mathrm{~K}^{-1}$, while the Leidenfrost and Korenic correlation [12] for finned in-line tube evaporative condensers gives $\alpha_{\mathrm{s}}=2920 \mathrm{~W} \mathrm{~m}^{-2} \mathrm{~K}^{-1}$. The model can be used to calculate $\left(\alpha_{\mathrm{s}}\right.$ and $\left.K_{\mathrm{m}}\right)$ when the outlet parameters of the heat exchanger from the experimental measurements are fed as input data. Fig. 5 shows a scatter of $\alpha_{\mathrm{s}}$ from the measurement data, which could also be noticed in the data presented by Mizushina et al. [2] and Dreyer and Erens [7]. The latter authors attributed it to high sensitivity of $\alpha_{\mathrm{s}}$ to variations of spray water temperature. This could also be valid for the scatter of the mass transfer coefficient $K_{\mathrm{m}}$. The average value of $\alpha_{\mathrm{s}}$ found from the experimental measurements for the finned tubes is $2268 \mathrm{~W} \mathrm{~m}^{-2} \mathrm{~K}^{-1}$, which is higher than that found for the plain tubes $\left(1898 \mathrm{~W} \mathrm{~m}^{-2} \mathrm{~K}^{-1}\right.$ ). For the average value of $\alpha_{\mathrm{s}}$ for the finned tubes, the Schmidt formula (Eq. (15)) involves $1.6 \%$ relative error in the fin efficiency compared to the exact solution (Eq. (13)).

The spray water resistance $\left(1 / \alpha_{\mathrm{s}}\right)$ is part of the overall resistance to heat transfer $\left(1 / U_{\mathrm{o}}\right)$ which includes the internal resistance of the hot water side and the tube wall resistance according to Eq. (2). The hot water flow rate was constant during the tests. $U_{\mathrm{o}}$ determines the outlet hot water temperature (or the heat load) according to Eq. (1). Therefore, the comparison of the heat transfer

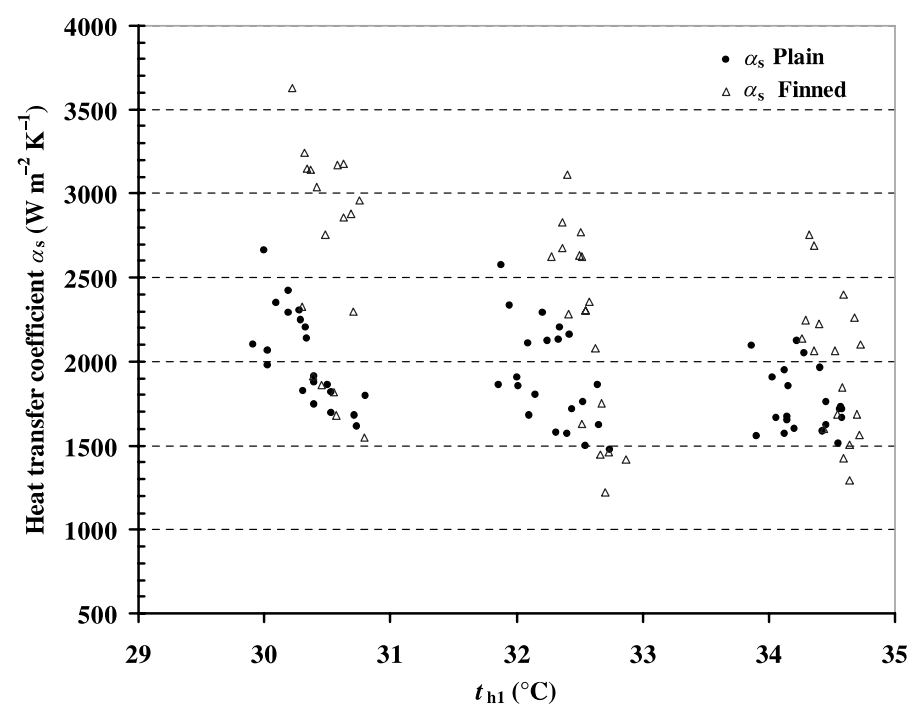

Fig. 5. Heat transfer coefficient $\alpha_{\mathrm{s}}$ for the plain and finned tubes from the measurement data. 


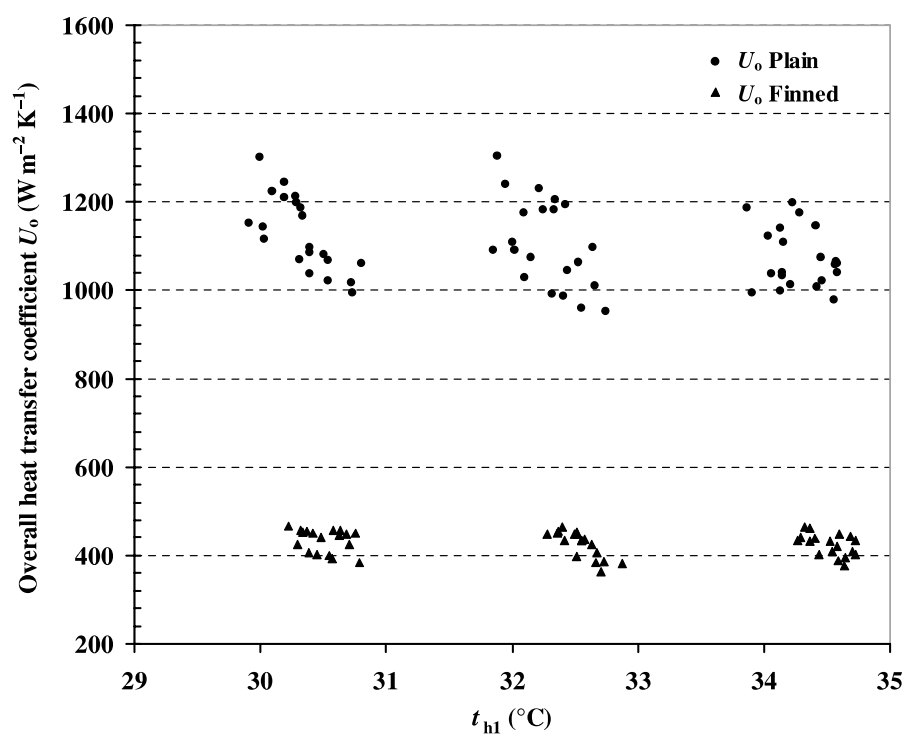

Fig. 6. Overall heat transfer coefficient $U_{\mathrm{o}}$ for the plain and finned tubes from the measurement data.

coefficients could be based on $U_{\mathrm{o}}$ which would include effects of variations of $\alpha_{\mathrm{s}}$ and geometry resulting from using the fins (Eq. (11)). Fig. 6 indicates a reduced scatter of $U_{\mathrm{o}}$ (for the plain tubes: $83 \%$ of the values are within a range of $\pm 10 \%$ of an average value of $1100 \mathrm{~W} \mathrm{~m}^{-2} \mathrm{~K}^{-1}$, while for the finned tubes $96 \%$ of the values are within the same range for an average of $428 \mathrm{~W} \mathrm{~m}^{-2} \mathrm{~K}^{-1}$ ). The ratio of the total contact area (finned tubes/plain tubes) is four, whereas the corresponding ratio of heat transfer rate ranges from 1.92 to 2.40. This means that $U_{\mathrm{o}}$ values (in $\mathrm{W} \mathrm{m}^{-2} \mathrm{~K}^{-1}$ ) for the plain tubes are higher than those for the finned tubes, and as shown by Fig. 6. However, the finned-tubes utilise much more heat transfer area, and their overall thermal performance is, therefore, higher.

The average fin efficiency $\eta_{\mathrm{f}}$ found from this work is $43 \%$. Wet fins have low efficiencies when compared with dry fins $[4,5,11]$, which is due to a relatively high heat transfer coefficient between the fin surface and the water film $\left(\alpha_{s}\right)$. A considerable decrease of fin efficiency was noticed in airconditioning applications for air cooling and dehumidification due to existence of moisture on the fin surface. Hong and Webb [19] indicated a decrease of $35 \%$ in $\eta_{\mathrm{f}}$ with increased relative humidity. The utilisation of wet extended surfaces will increase the total mass transfer from the spray water which will increase heat transfer from the hot water, despite the fact that fin efficiency could be low.

Fig. 7 shows the mass transfer coefficients $K_{\mathrm{m}}\left(\right.$ in $\left.\mathrm{kg} \mathrm{s}^{-1} \mathrm{~m}^{-2}\right)$ for the plain and finned tubes as a function of the air flow rate $m_{\mathrm{a}}$. The plain tubes have higher $K_{\mathrm{m}}$ values, whereas the ratio of total contact area (finned tubes/plain tubes) is four, which results in higher heat transfer rates for the finned tubes.

A trend of dependency of $K_{\mathrm{m}}$ on $t_{\mathrm{h} 1}$ and $\alpha_{\mathrm{s}}$ on air flow rate $m_{\mathrm{a}}$, are noticed in the measurements data. Nevertheless, the physical analysis does not show a direct relation. The reason could be effects of $t_{\mathrm{h} 1}$ and $m_{\mathrm{a}}$ on the spray water temperature $t_{\mathrm{s}}$ inside the heat exchanger, where $t_{\mathrm{s}}$ determines the transfer coefficients $\left(\alpha_{\mathrm{s}}\right.$ and $K_{\mathrm{m}}$ ) according to Eqs. (1) and (3), respectively. For the mass 


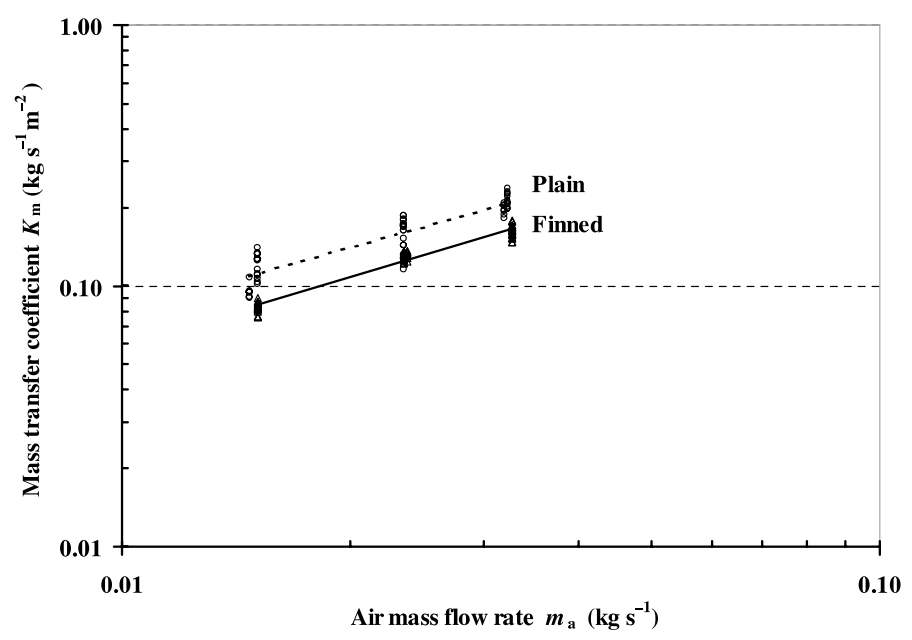

Fig. 7. Mass transfer coefficient $K_{\mathrm{m}}$ for the plain and finned tubes from the measurement data.

transfer between the spray water around the tubes and air, the Sherwood number $(S h)$ could be expressed in terms of air Reynolds number $\left(R e_{\mathrm{a}}\right)$ and Schmidt number $(S c)$ in the form

$$
S h=n_{1}\left(\operatorname{Re}_{\mathrm{a}}\right)^{n_{2}}(S c)^{n_{3}}
$$

where $n_{1}, n_{2}$ and $n_{3}$ are constants. There is no general agreement for the definition of the characteristic length in $S h$ and $R e_{\mathrm{a}}$ for finned tubes. However, for specific dimensions and operating temperatures, the mass transfer coefficient could be considered as a function of air flow rate only. Therefore, the correlations for the data presented in Fig. 7 are

$$
\begin{array}{ll}
K_{\mathrm{m}}=3.36 m_{\mathrm{a}}^{0.812} & \text { for the plain tubes } \\
K_{\mathrm{m}}=3.29 m_{\mathrm{a}}^{0.874} & \text { for the finned tubes. }
\end{array}
$$

These correlations are demonstrated in Fig. 8 with correlations from other works. For plain tubes, the powers of $m_{\mathrm{a}}$ from other correlations are 0.8 from Niitsu et al. $16 \mathrm{~mm}$ tube [4], 0.773 from Hasan and Sirén $10 \mathrm{~mm}$ [9], 0.905 from Parker and Treybal $19 \mathrm{~mm}$ [1], and 0.9 from Mizushina et al. $19 \mathrm{~mm}$ [2]. The correlation for the current work falls between that concluded from measurements for a CWCT prototype using the computational model [9] and Niitsu et al. [4]. For finned tubes, Niitsu et al. [4] indicated a power of 1.25 for $m_{\mathrm{a}}$ for $16 \mathrm{~mm}$ tubes using two fin spacing $(6.1$ and $11 \mathrm{~mm})$. Their correlations give lower mass transfer coefficients than that obtained from the current work, possibly due to water hold up between the fins in their work. Using the average values of $\alpha_{\mathrm{s}}$ and values of $K_{\mathrm{m}}$ from Eqs. (20) and (21) in the model to estimate the heat load shows that the absolute error is less than $10 \%$ for $89 \%$ of the measurement data for the plain tubes, and less than $5 \%$ for $96 \%$ of the data for the finned tubes.

Due to penetration of spray water droplets in the pressure measuring taps, it was only possible to measure the air pressure drop for the wet operation of the finned tubes, while it was not reliable for the plain tubes. To avoid this interference and effects of inlet-duct shape, a separate rig was built to measure the pressure drop across the tube banks in a dry mode. The pressure drop 


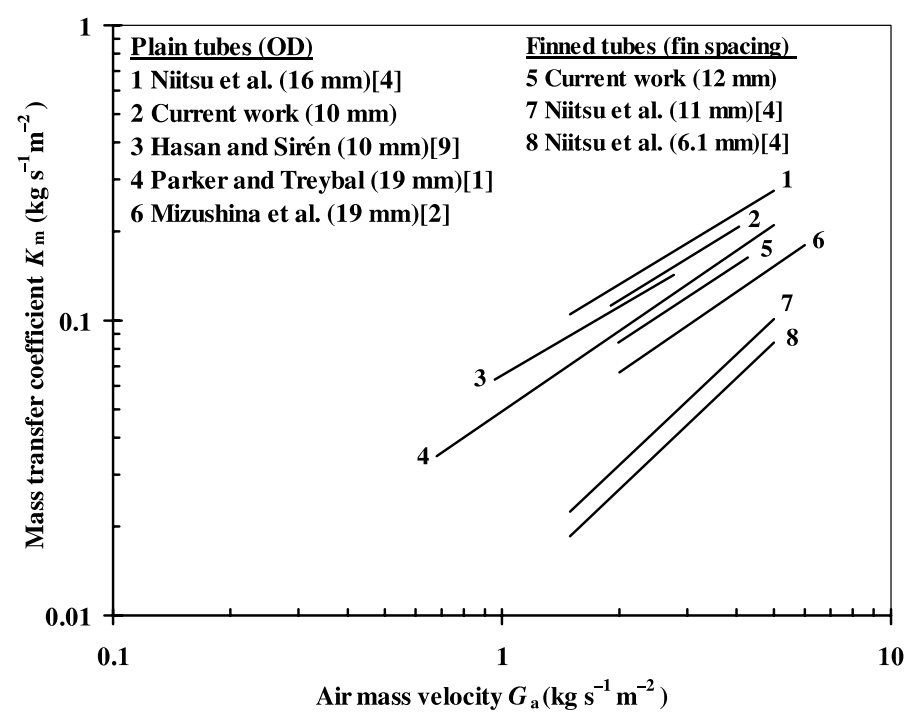

Fig. 8. Mass transfer coefficient $K_{\mathrm{m}}$ for plain and finned tubes for different works.

for the finned tube was higher than that for the plain tubes, with a small increase for the wet operation.

Introducing an energy index $(E)$ to refer to the relative thermal-hydraulic characteristics of any heat exchanger, defined as the ratio of volumetric thermal conductance $\left(U_{\mathrm{o}} A_{\mathrm{t}} / V\right)$ to air pressure drop per unit length $(\Delta p / z)$ :

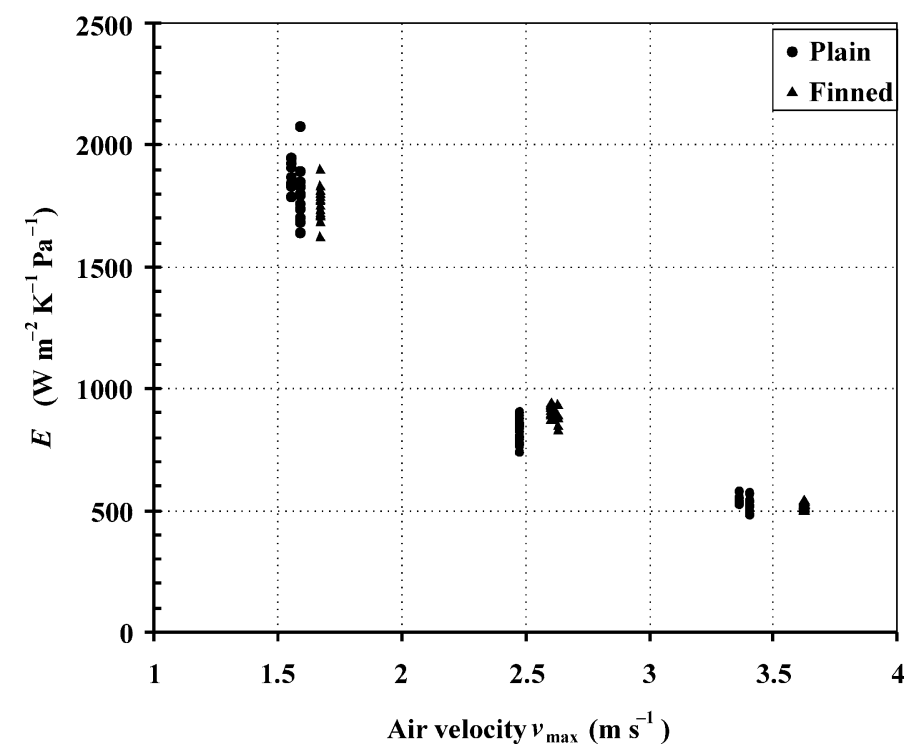

Fig. 9. Energy index for the plain and finned tube heat exchangers. 


$$
E=\frac{U_{\mathrm{o}} A_{\mathrm{t}} / V}{\Delta p / z}
$$

where $\Delta p$ is the air pressure drop across the heat exchanger tubes and $V$ is the volume ( $V=A_{\mathrm{cs}} z$, where $A_{\mathrm{cs}}$ is the cross sectional area). The thermal conductance is $U_{\mathrm{o}} A_{\mathrm{t}}=q / \Delta t_{\mathrm{lm}}$ where $\Delta t_{\mathrm{lm}}$ is the log-mean temperature difference. Since $q=m_{\mathrm{h}} C\left(t_{\mathrm{h} 1}-t_{\mathrm{h} 2}\right)$, therefore $E$ can be rewritten as

$$
E=\frac{m_{\mathrm{h}} C}{A_{\mathrm{cs}} \Delta p} \ln \left(\frac{t_{\mathrm{h} 1}-\overline{t_{\mathrm{s}}}}{t_{\mathrm{h} 2}-\overline{t_{\mathrm{s}}}}\right)
$$

The energy index $E$ is shown versus $v_{\max }$ in Fig. 9, where $v_{\max }$ is the air velocity in the minimum cross section between the tubes for a dry case. It appears from this figure that the plain tubes and the finned tubes have close energy indices. This means that for a specific volume, the finned tubes transfer higher rates of heat with the same energy index.

\section{Conclusions}

A considerable increase in heat transfer takes place when using plate-finned tube evaporatively cooled heat exchangers compared with plain tubes, both occupying the same volume. The increase is from $92 \%$ to $140 \%$ for the range of operating conditions. An assumption of constant spray water temperature is considered, which results in simplifications of the calculation of total heat transfer. A model is developed to calculate the performance of plain and finned tubes. The heat transfer coefficient between the tube wall and the spray water film $\alpha_{\mathrm{s}}$ and the mass transfer coefficient $K_{\mathrm{m}}$ are found from the measurement data. The overall heat transfer coefficient $U_{\mathrm{o}}$ and the mass transfer coefficient $K_{\mathrm{m}}$ appeared to be lower for the finned tubes. However, since the total area ratio (finned tubes/plain tubes) is higher, its thermal performance is higher. For wet surfaces, the fin efficiency undergoes a significant decrease due to a relatively high heat transfer coefficient compared with dry fins. The average fin efficiency for this work is found to be $43 \%$. No water hold up was seen between the fin-plates. For a specific volume, the combined thermal-hydraulic characteristics show higher rate of heat transfer for the finned tubes with close energy index.

\section{Acknowledgements}

Acknowledgements are due to laboratory engineer Markku Sivukari and the technical staff of the HVAC Laboratory, Helsinki University of Technology for their efforts in building the experimental rig.

\section{References}

[1] R.O. Parker, R.E. Treybal, The heat-mass transfer characteristics of evaporative coolers, Chemical Engineering Progress Symposium Series 57 (32) (1962) 138-149.

[2] T. Mizushina, R. Ito, H. Miyashita, Experimental study of an evaporative cooler, International Chemical Engineering 7 (4) (1967) 727-732. 
[3] T. Mizushina, R. Ito, H. Miyashita, Characteristics and methods of thermal design of evaporative cooler, International Chemical Engineering 8 (3) (1968) 532-538.

[4] Y. Niitsu, K. Naito, T. Anzai, Studies on characteristics and design procedure of evaporative coolers, Journal of SHASE, Japan 43 (7) (1969).

[5] P.J. Erens, Comparison of some design choices for evaporative cooler cores, Heat Transfer Engineering 9 (2) (1988) 29-35.

[6] Y.L. Tsay, Analysis of heat and mass transfer in a countercurrent-flow wet surface heat exchanger, International Journal of Heat and Fluid Flow 15 (2) (1994) 149-156.

[7] A.A. Dreyer, P.J. Erens, Heat and mass transfer coefficient and pressure drop correlations for a crossflow evaporative cooler, in: Proceedings of the Ninth International Heat Transfer Conference, vol. 6, Hemisphere Publ. Co., New York, USA, 1990, pp. 233-238.

[8] D. Peterson, D. Glasser, D. Williams, R. Ramsden, Predicting the performance of an evaporative condenser, Journal of Heat Transfer-Transactions of ASME 110 (1988) 748-753.

[9] A. Hasan, K. Sirén, Theoretical and computational analysis of closed wet cooling towers and its applications in cooling of buildings, Energy and Buildings 34 (5) (2002) 477-486.

[10] A. Hasan, G. Gan, Simplification of analytical models and incorporation with CFD for the performance prediction of closed wet cooling towers, International Journal of Energy Research 26 (13) (2002) 1161-1174.

[11] D.K. Kried, B.M. Johnson, D.W. Faletti, Approximate analysis of heat transfer from the surface of a wet finned heat exchanger, ASME paper 78-HT-26, 1978.

[12] W. Leidenfrost, B. Korenic, Principles of evaporative cooling and heat transfer augmentation, in: N.P. Cheremisinoff (Ed.), Handbook of Heat and Mass Transfer, vol. 1, Gulf Publishing, Houston, 1986, pp. 1025-1063.

[13] F. Merkel, Verdunstungskuehlung, VDI Forschungsarbeiten No. 275, Berlin, 1925.

[14] J.L. Threlkeld, Thermal Environmental Engineering, second ed., Prentice-Hall Inc., NJ, 1970.

[15] F.P. Incropera, D.P. DeWitt, Fundamentals of Heat and Mass Transfer, fourth ed., John Wiley and Sons, 1996.

[16] T.E. Schmidt, Heat transfer calculations for extended surfaces, Refrigerating Engineering 4 (1949) 351-357.

[17] I.C. Finlay, D. Harris, Evaporative cooling of tube banks, International Journal of Refrigeration 7 (4) (1984) 214 224.

[18] W.H. McAdams, T.B. Drew, G.S. Bays, ASME Transactions 62 (1940) 627-631.

[19] K.T. Hong, R.L. Webb, Calculation of fin efficiency for wet and dry fins, HVAC \& R Research 2 (1) (1996) 27-41. 